\title{
Os Odontoideum: A Single-Center Experience with Controversies in Management and Evolution of Treatment Strategies
}

\author{
Vamsi Krishna Yerramneni ${ }^{1} \quad$ Neeraj Sharma ${ }^{1}$ \\ ${ }^{1}$ Department of Neurosurgery, Nizam's Institute of Medical \\ Sciences, Punjagutta, Hyderabad, Telangana, India
}

\begin{abstract}
Address for correspondence Vamsi Krishna Yerramneni, MBBS, MCh, Department of Neurosurgery, Nizam's Institute of Medical Sciences, Punjagutta, Hyderabad 500082, Telangana, India (e-mail: vamsiky.ns@gmail.com).
\end{abstract}
Abstract
Keywords
- os odontoideum
- etiology
- treatment options
- controversies of management

Os odontoideum is an independent ossicle of variable size and shape separated from the body of C2. There are various theories on the etiology. Different hypothesis on etiology include traumatic and congenital. Because of the laxity of the ligaments associated with the anomalous odontoid, there can be associated instability at the craniovertebral junction. The authors presented their experience of treating these anomalies, their clinical presentations, evolution of the treatment strategies over years, and a brief review of literature on etiopathogenesis.

\section{Introduction}

Os odontoideum $(\mathrm{OO})$ is an anomaly of the body of the axis in a particular odontoid, identified as a smooth, independent ossicle of variable size and shape separated from the base of a shortened odontoid process by an obvious gap, with no osseous connection to the body of $\mathrm{C} 2$.

There are various hypotheses on the genesis of 00 , including traumatic and developmental. ${ }^{1-6}$ Orthotopic $\mathrm{OO}$ lies in the normal position on the odontoid process, moving with the atlas anterior arch, whereas the dystopic morphology describes an ossicle fused to the basion. ${ }^{3}$

The etiology and some of the aspects of the management remain controversial till date.

The authors analyzed the cases of the 00 treated at their institution to look at the etiologic aspects, common clinical presentations, treatment strategies adopted, evolution of management patterns, and the long-term results to derive conclusions regarding the appropriate management strategies.

\section{Materials and Methods}

Between 2004 and 2017, the authors treated 1800 patients at Nizam's Institute of Medical Sciences, Hyderabad, India.
Retrospectively, the data were obtained from the hospital records and the patients were followed up.

All patients underwent neutral, flexion, and extension radiographs of the craniovertebral junction (CVJ), and computed tomography (CT) and magnetic resonance imaging (MRI) of the CVJ. CT angiographies of the vertebral arteries were done as part of standard workup to look for vertebral artery anomalies since 2012.

Preoperative clinical evaluation was done, and Nurick's grading was used for comparison of the functional outcomes.

The main concern in $\mathrm{OO}$ is atlantoaxial dislocation (AAD) and the attending cord compression from it. The basic philosophy of treatment of $\mathrm{OO}$ is addressing the instability at atlantoaxial joint by fixation methods. The choice of surgical procedure was based on the surgeon's expertise and the comfort with a particular fixation method. In the initial years, the choice was mainly $\mathrm{C} 1 \mathrm{C} 2$ wiring methods or occipitocervical fusions; however, the later years saw growing expertise in $\mathrm{C} 1 \mathrm{C} 2$ fixation methods. Therefore, the $\mathrm{C} 1 \mathrm{C} 2$ fixation methods have become the standard of treatment for OO. In patients with no instability and associated Chiari's malformations, only foramen magnum decompression was performed to address the symptoms arising out of the tonsillar decent. $\mathrm{C} 1 \mathrm{C} 2$ fusion procedure was performed even in asymptomatic cases.
DOI https://doi.org/ $10.1055 / \mathrm{s}-0039-1686960$ ISSN 2277-954X.

\section{(c) 2021. Neurological Surgeons' Society of India.}

This is an open access article published by Thieme under the terms of the Creative Commons Attribution-NonDerivative-NonCommercial-License, permitting copying and reproduction so long as the original work is given appropriate credit. Contents may not be used for commercial purposes, or adapted, remixed, transformed or built upon. (https://creativecommons.org/licenses/by-nc-nd/4.0/).

Thieme Medical and Scientific Publishers Pvt. Ltd. A-12, 2nd Floor, Sector 2, Noida-201301 UP, India 
Postoperative follow-up was done at 3, 6, 12 months, and then once every year.

\section{Results}

Most patients presented from the first to third decades of their life. There was almost equal incidence in both male and female ( Table 1 ).

Table 1 Patient characteristics of 18 patients

\begin{tabular}{|l|l|}
\hline Total no of patients & 18 \\
\hline Male-to-female ratio & $10: 8$ \\
\hline Age (mean) & $25.93 \pm 16.05$ (6-65) \\
\hline Preoperative Nurick's grade & $1.64 \pm 0.99$ \\
\hline Postoperative Nurick's grade & $1.25 \pm 0.55$ \\
\hline Clinical symptoms & \\
\hline Asymptomatic & 1 \\
\hline Neck pain & 4 \\
\hline Quadriparesis following trivial trauma & 6 \\
\hline Progressive quadriparesis & 7 \\
\hline Associated radiologic features & \\
\hline Atlantoaxial dislocation (AAD) & 17 \\
\hline BI & 1 \\
\hline Chiari's malformation with syrinx & 1 \\
\hline Other associated syndromes & \\
\hline Down's syndromes & 1 \\
\hline Scoliosis & 1 \\
\hline Surgical procedures & 2 \\
\hline C1C2 wiring & 2 \\
\hline C1C2 transarticular screws & 11 \\
\hline $\begin{array}{l}\text { C1 lateral mass and C2 pedicle } \\
\text { screw fixation }\end{array}$ & 2 \\
\hline Occipitocervical fusion & 1 \\
\hline Foramen magnum decompression & $20.82 \pm 20.57$ \\
\hline Average follow-up in months & \\
\hline
\end{tabular}

\section{Presentation}

Though the common presentation was quadriparesis (13/18), the important observation is that 6 out of 18 patients were diagnosed with 00 when they developed quadriparesis following trivial trauma. Six patients had history of significant injury such as fall from height during their childhood before they were diagnosed with 00 . The significance of this trauma cannot be assessed as none of these patients had imaging prior to the significant trauma.

One patient had Chiari's malformation with syrinx with no AAD. The patient underwent foramen magnum decompression.

Until 2014 different surgeons of our hospital used different surgical techniques, including OCF (occipitocervical fusion), C1C2 wiring, and C1C2 transarticular screw placement. The surgical technique was based on the surgeon's expertise and comfortable with a particular technique.

After 2014, C1 lateral mass and C2 pedicle screw technique has become the standard technique for $\mathrm{OO}$ with AAD treatment (-Figs. 1 and 2). In two cases of 00, the authors implanted cages in the $\mathrm{C} 1 \mathrm{C} 2$ joint to achieve distraction and further manipulation of joint to achieve complete reduction in the $\mathrm{AAD}$, thereby proper alignment at the CVJ.

There were no major surgical complications in the immediate postoperative period.

Average follow-up of the patients was $20.82 \pm 20.57$. Bone fusion was good in all cases of OCF. C1C2 fixation did not show well evident bone formation, but there was no screw pull-out or implant failure observed during follow-up. In one patient who underwent $\mathrm{C} 1 \mathrm{C} 2$ wiring, there was no evident bone fusion on X-rays. However, there was no implant failure or breakage of wires.

\section{Discussion}

Os odontoideum is a rare anomaly of the odontoid process first described by Giacomini in 1886. There is considerable controversy regarding the etiology of the 00 about whether it is congenital or traumatic. The proponents of the congenital

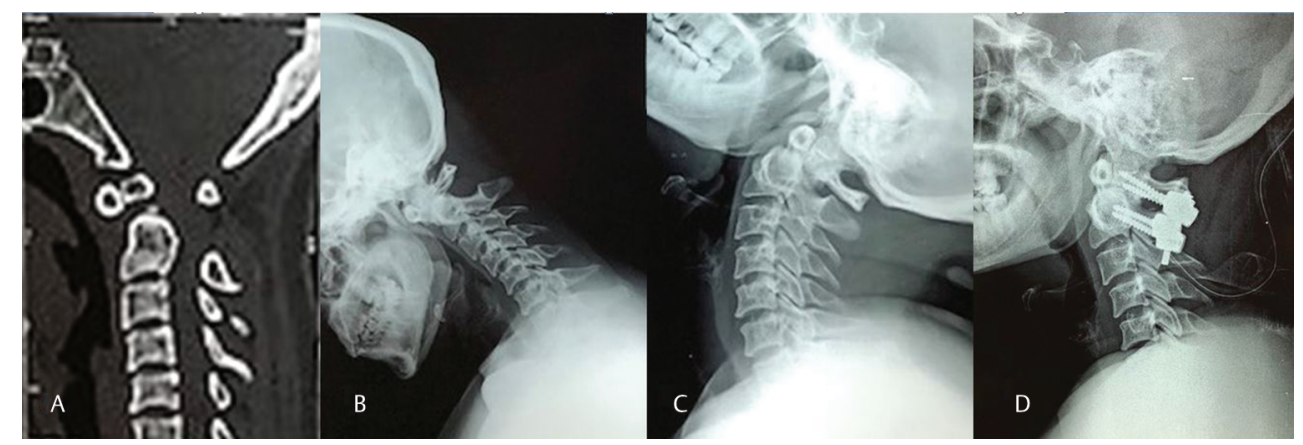

Fig. 1 A 38-year-old woman presented with quadriparesis after a trivial fall while walking. (A) CT sagittal film of showing orthotopic os odontoideum (OO). The fusion of the $\mathrm{OO}$ to the ring of the $\mathrm{C} 1$ arch is noted. (B, C) Lateral view flexion and extension of X-ray of CVJ showing odontoideum fragment moving on flexion and extension. In flexion, because of an incompetent odontoid, the posterior ring of the $\mathrm{C} 1$ arch moves forward and encroaches on to the spinal canal compressing the spinal cord. In extension, the fused $\mathrm{C} 1$ arch and the $\mathrm{OO}$ move posteriorly and cause compression over the spinal cord. (D) Postoperative X-ray after C1 lateral mass and C2 pedicle screw fixation. Restoration of alignment appreciated. 


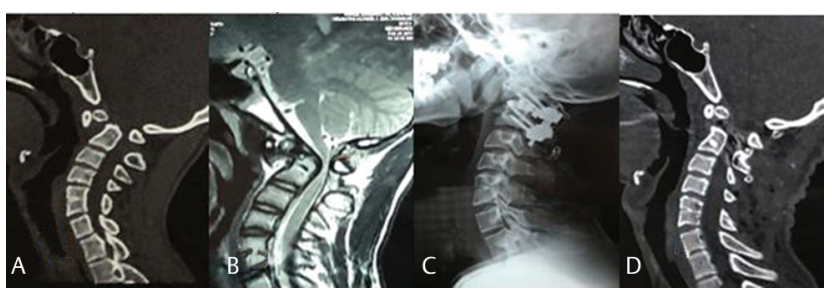

Fig. 2 A 17-year-old boy presenting with quadriparesis following fall while playing. He as well had neck pain at the time of presentation. (A) CT sagittal section showing dystopic os odontoideum (OO). The $\mathrm{OO}$ is out of alignment with the odontoid. (B) MRI sagittal section showing atlantoaxial dislocation (AAD) and compression of the cervicomedullary junction (CMJ). The flexion and extension X-rays of the (not shown in the picture) craniovertebral junction (CVJ) not showing any reduction in the AAD. C1 lateral mass and C2 pedicle screw fixation with cage placement in the joints and compression of the screw heads posteriorly achieved the reduction in the AAD. (C, D) Postoperative $X$-ray of CV] and the $C T$ sagittal section showing screws and the final alignment achieved.

etiology hypothesize that the $\mathrm{OO}$ is the result of the failure of the dens to fuse with the body of the $\mathrm{C} 2 .^{3}$ This hypothesis is based on the observations that $\mathrm{OO}$ is present in twins, ${ }^{2-4}$ in cases with congenital syndromes and other associated anomalies at the CVJ.,7-13 It was believed that $\mathrm{OO}$ is caused by a failure of fusion between the first and second sclerotomes. However, this theory has been questioned because the neurocentral synchondrosis is located below the level of the superior articulating facet, whereas the gap in 00 is frequently located above the plane of the superior articulating facet.

This gave rise to the traumatic origin hypothesis. Fielding et al suggested that with a fracture or disruption through the neurocentral synchondrosis, the alar ligaments that attach to the apex of the odontoid may gradually distract the fragment away from the base. The apex and base of the odontoid continue to have adequate perfusion, but the midportion suffers from lack of blood supply and thus contributes to poor healing. ${ }^{5}$ This is supported by the observation that many 00 patients had a remote trauma in their childhood. ${ }^{14}$ The "traumatic cause" hypothesis is supported by case reports of patients with a previously documented intact C2 who later were found to have 00 after remote trauma. Schuler et al reported on a 2-year-old patient who fell out of her crib and complained of neck pain; her initial cervical X-ray was normal. After continued neck pain, repeat cervical X-rays were obtained 13 months after her injury, which demonstrated 00 with atlantoaxial instability. ${ }^{16}$ Zygourakis et al, in their report of 2-year-old girl who had C1-2 ligamentous injury demonstrated with subsequent development of the 00 , proposed that the development of the $\mathrm{OO}$ is as a result of the culmination of the trauma and vascular compromise. ${ }^{7}$

In this series, there were six patients who had a history of significant trauma in their childhood; however, none of them was investigated in the period following it. Therefore, it is difficult to derive any conclusion out of the aforementioned observations about the etiology of 00.

\section{Clinical Presentation}

The presentation of $\mathrm{OO}$ can be an asymptomatic patients in whom $\mathrm{OO}$ is an incidental discovery, neck pain, headache, compressive myelopathy, presentation with quadriparesis, or quadriplegia after a traumatic event. ${ }^{16,17}$ In this series, one patient was incidentally diagnosed to have 00 , when she had cervical X-rays as part of workup for scoliosis. Investigation of occasional neck pain revealed 00 in some. Development of quadriparesis following trivial trauma in six patients in this series supports the argument that even asymptomatic patients may require surgical treatment, particularly in this setup.

Os odontoideum can be clearly visualized using plain radiographs with the open mouth, anteroposterior, and lateral views. In addition, plain dynamic lateral radiographs (performed in flexion and extension) can further evaluate atlantoaxial instability. However, CT of the CVJ, CT angiography, and MRI of the CVJ are important to better understand the bony anatomy and soft tissue compression. Though various parameters such as space available for the cord and instability index have been proposed, they may not reflect the true instability at the CVJ. ${ }^{18,19}$

\section{Management}

All patients who are symptomatic and have neck pain or compressive myelopathy need surgical treatment. There is controversy regarding the management of asymptomatic 00. Some propose follow-up whereas others prefer treatment on case-to-case basis. We believe asymptomatic patients stand significant risk of deterioration even on minor trauma as is evident from the high number of patients in this series presenting for the first time after a trivial injury. In addition, considering the reports of sudden deaths, deterioration after incidents of minor trauma, gives the impression that surgery should be strongly considered even in asymptomatic patients. ${ }^{20-21}$ Factors such as age, activity level, and radiographic findings, including evidence of atlantoaxial instability and anatomy favorable for surgical instrumentation need to be considered before opting for a conservative approach.

C1C2 fixations have emerged as the procedure of choice because they offer the advantage of retaining neck motion except neck rotation. As the authors perform the $\mathrm{C} 1$ lateral mass, $\mathrm{C} 2$ pedicle screws placement with joint distraction techniques for the CVJ with greater ease, these techniques have become the favorable for treatment of OO. The $\mathrm{C} 1 \mathrm{C} 2$ distraction techniques with cage placement were especially considered when the patient has AAD, which is not completely reducible (-Fig. 2). Foramen magnum decompression alone can be considered for patients of $\mathrm{OO}$ with no obvious instability at $\mathrm{C} 1 \mathrm{C} 2$. However, the C1C2 joint distraction techniques for treatment of Chiari's malformations as proposed by Goel can also be considered. ${ }^{21,22}$ 


\section{Conclusion}

Os odontoideum etiology is controversial, but vascular insult either before or after birth seems to cause it. Majority of $\mathrm{OO}$ are associated with significant instability at atlantoaxial joint. Surgical treatment of even asymptomatic patients may be a better option in Indian setting. C1C2 fixations techniques seem to be superior to other techniques in terms of offering stability as well as minimal restriction of movements.

\section{Conflict of Interest}

None declared.

\section{References}

1 Kirlew KA, Hathout GM, Reiter SD, Gold RH. Os odontoideum in identical twins: perspectives on etiology. Skeletal Radiol 1993;22(7):525-527

2 Morgan MK, Onofrio BM, Bender CE. Familial os odontoideum. Case report. J Neurosurg 1989;70(4):636-639

3 Wang S, Wang C. Familial dystopic os odontoideum: a report of three cases. J Bone Joint Surg Am 2011;93(9):e44

4 Currarino G. Segmentation defect in the midodontoid process and its possible relationship to the congenital type of os odontoideum. Pediatr Radiol 2002;32(1):34-40

5 Fielding JW, Hensinger RN, Hawkins RJ. Os odontoideum. J Bone Joint Surg Am 1980;62(3):376-383

6 Zygourakis CC, Cahill KS, Proctor MR. Delayed development of os odontoideum after traumatic cervical injury: support for a vascular etiology. J Neurosurg Pediatr 2011;7(2):201-204

7 Osti M, Philipp H, Meusburger B, Benedetto KP. Os odontoideum with bipartite atlas and segmental instability: a case report. Eur Spine J 2006;15(Suppl 5):564-567

8 Stevens JM, Chong WK, Barber C, Kendall BE, Crockard HA. A new appraisal of abnormalities of the odontoid process associated with atlanto-axial subluxation and neurological disability. Brain 1994;117(Pt 1):133-148
9 Yukata K, Katoh S, Sairyo K, Matsui Y, Hamada Y, Yasui N. Os odontoideum in achondroplasia: a case report. J Pediatr Orthop B 2008;17(2):103-105

10 Kornreich L, Horev G, Schwarz M, Karmazyn B, Laron Z. Laron syndrome abnormalities: spinal stenosis, os odontoideum, degenerative changes of the atlanto-odontoid joint, and small oropharynx. AJNR Am J Neuroradiol 2002;23(4):625-631

11 Dias RP, Buchanan CR, Thomas N, et al. Os odontoideum in wolcott-rallison syndrome: a case series of 4 patients. Orphanet J Rare Dis 2016;11:14

12 Bethem D. Os odontoideum in chondrodystrophia calcificans congenita. A case report. J Bone Joint Surg Am 1982;64(9):1385-1386

13 Menezes AH. Pathogenesis, dynamics, and management of os odontoideum. Neurosurg Focus 1999;6(6):e2

14 Schuler TC, Kurz L, Thompson DE, Zemenick G, Hensinger RN, Herkowitz HN. Natural history of os odontoideum. J Pediatr Orthop 1991;11(2):222-225

15 Klimo P Jr, Kan P, Rao G, Apfelbaum R, Brockmeyer D. Os odontoideum: presentation, diagnosis, and treatment in a series of 78 patients. J Neurosurg Spine 2008;9(4):332-342

16 Rowland LP, Shapiro JH, Jacobson HG. Neurological syndromes associated with congenital absence of the odontoid process. AMA Arch Neurol Psychiatry 1958;80(3):286-291

17 Watanabe M, Toyama Y, Fujimura Y. Atlantoaxial instability in os odontoideum with myelopathy. Spine 1996;21(12): $1435-1439$

18 Abe H, Tsuru M, Mitsumori K. [Atlanto-axial dislocationinstability index and indications for surgery] [author's transl]. No Shinkei Geka 1976;4(1):57-72

19 Michaels L, Prevost MJ, Crang DF. Pathological changes in a case of os odontoideum (separate odontoid process). J Bone Joint Surg Am 1969;51(5):965-972

20 Dai L, Yuan W, Ni B, Jia L. Os odontoideum: etiology, diagnosis, and management. Surg Neurol 2000;53(2):106-108, discussion 108-109

21 Goel A. Is atlantoaxial instability the cause of Chiari malformation? Outcome analysis of 65 patients treated by atlantoaxial fixation. J Neurosurg Spine 2015;22(2):116-127

22 Goel A. Response. J Neurosurg Spine 2015;22(2):114-115 